\section{Yamada Science $\&$ Art Corporation}

Environmental Consultants

HOTMAC / RAPTAD (New Version)

- 3-D atmospheric modeling

- Airflow over complex terrain

- Diffusion \& transport simulations

RESEARCH \& DEVELOPMENT

- Advanced turbulence modeling

- Precipitation / fog forecast

CONSULTING

- Environmental assessments

- Case studies

See us at Booth \#639
AWMA Annual Meeting \& Exhibition
at Colorado Convention Center
Denver, June 15-17, 1993

147 Monte Rey Dr. S., Los Alamos, NM 87544

Phone: (505) 672-3373 Fax: (505) 672-1910 conditions on a regional level, enabling scientists to piece together a picture of global atmospheric conditions.

A commercial satellite company has agreed to launch a low-earth orbit satellite receiver under the auspices of the University Navstar Consortium, a group of 46 research institutions that use the GPS for science applications. The group is seeking additional funding for the project's other costs.

As uses for the GPS have expanded, geophysicists are using it to measure the motion of earth's crust, including earthquakes. GPS surveys can fix positions with an accuracy of about one centimeter, and the earth's crust typically moves several centimeters each year. The system can measure the relative distance, or the distance between two points, even better than it can determine the location of any single point.

Begun in the mid-1980s, the GPS was originally designed to gather very precise data on positioning for navigation of both military and civilian vehicles. There are now 19 satellites in place. Next year the system will be complete with 21 satellites.

For additional information, contact Laura Herbst, North Carolina State University Information Services, NCSU, Box 7504, Raleigh, NC 27695; phone: 919515-3470.

\title{
25 years ago
}

Editor's note: More than 30 pages of the May 1968 Bulletin were devoted to the Harry Wexler Memorial Lecture presented by Jerome Namias at the preceding January meeting of the Society in San Francisco. In Namias's own words: "We [Harry and he] were close friends—and at times competitors - throughout grammar,

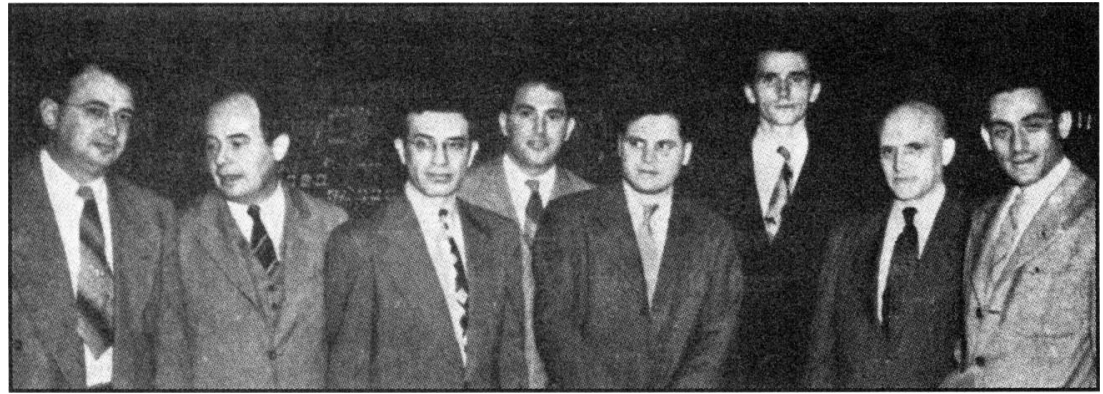

Photo taken in front of the ENIAC, Aberdeen Proving Ground, 4 April 1950, on occasion of the first numerical weather computations carried out with aid of a high-speed automatic computer. (Pictured left to right: H. Wexler, J. von Neumann, M. H. Frankel, J. Namias, J. C. Freeman, R. Fjortoft, F. W. Reichelderfer and J. G. Charney.) junior high, and high school. We lived a few blocks from each other in Fall River, Massachusetts, were members of the same Boy Scout troop, dated together, married sisters, and carried on the major part of our careers in the U.S. Weather Bureau." The lecture dealt with longrange weather forecasting, its history, current status and outlook and was accompanied by this noteworthy photograph.

Bull. Amer. Meteor. Soc., 49, 439. 